\title{
Adult Attachment and the Break-Up of Romantic Relationships
}

\author{
Marian J. Bakermans-Kranenburg \\ Marinus H. van IJzendoorn
}

\begin{abstract}
The study of the break-up of romantic relationships was integrated into research on adults' attachment representations. Eighty-three female subjects, currently married mothers of one child, werc given the Adult Attachment Interview (AAI; George, Kaplan, \& Main, 1985), supplemented with questions about the break-up of relationships with former husbands or boyfriends. Subjects who were classified as Unresolved with respect to loss to death of a close person more often indicated that they had experienced the break-up of romantic relationships and they also reported a larger number of former relationships. All subjects who had former romantic relationships indicated that they-and not their partners-decided to break up the relationship. With a more exploratory aim, we examined whether the AAI scoring system for unresolved loss (Main, DeMoss, \& Hesse, 1991) could also be used for determining whether subjects have come to
\end{abstract}

Marian J. Bakermans-Kranenburg, PhD, and Marinus H. van IJzendoorn, $\mathrm{PhD}$, are on the faculty of Centre for Child and Family Studies at Leiden University, P.O. Box 9555, 2300 RB Leiden, The Netherlands.

This research was supported by a Pioneer grant (No. PGS 59-256) from the Netherlands Organization for Scientific Research (NWO) to Marinus H. van IJzendoorn.

We gratefully acknowledge the help of Corine de Ruiter, Marianne de Wolff, Carmen Joosten, Connie Kruse, Stella van Rijsoort, Hylda Zwart-Woudstra, and Mariska Zwinkels in collecting and coding the data. We also thank Francisca Bijkerk, Bart Bosman, Dineke den Boer, Ciska Dijkstra, Bertilla van den Bovenkamp, and Adinda van Veen for transcribing the interviews. We extend special thanks to the subjects who participated in the study.

Address correspondence to Marian J. Bakermans-Kranenburg, Centre for Child and Family Studies, Leiden University, P.O. Box 9555, NL-2300 RB Leiden, The Netherlands.

Journal of Divorce \& Remarriage, Vol. 27 (3/4) 1997

(C) 1997 by The Haworth Press, Inc. All rights reserved. 
terms with the break-up of a romantic relationship. Although scores could be assigned reliably, results could not easily be interpreted: Subjects who were classified as unresolved with respect to the breakup of a romantic relationship appeared to be more sociable, and less fearful. Subjects who were classified as unresolved due to a loss through death were more often classified as not unresolved regarding the break-up of their romantic relationships. [Article copies available for a fee from The Haworth Document Delivery Service: 1-800-342-9678. E-mail address: getinfo@haworth.com]

In attachment theory and research, ample attention has been given to experiences of loss. One volume of John Bowlby's trilogy "Attachment and Loss" was entirely devoted to this topic (Bowlby, 1980). Bowlby (1980, p. 18) defined mourning as "the psychological processes, conscious and unconscious, that are set in train by the loss of a loved object and that commonly lead to the relinquishing of the object." He outlined four phases that occur in normal grieving of individuals who respond to the loss of a close relative: (1) shock and numbness, (2) searching and yearning, (3) disorganization and despair, and (4) reorientation and reorganization. In healthy mourning, the individual gradually comes to recognize and accept that the loss is permanent and comes to a redefinition of himself as well as of his situation. For instance, no longer is a man who lost his wife a husband but a widower; no longer is he one of a pair with complementary roles but a singleton (Bowlby, 1980, p. 94).

In recent years, the development of the Adult Attachment Interview (George, Kaplan, \& Main, 1985)-an instrument to assess adults' mental representations of attachment relationships-enabled researchers to systematically examine subjects' continuing unresolved states of mind with respect to experiences of loss through death. Main, DeMoss and Hesse (1991) developed a scale to assess lack of resolution of mourning as appearing from individuals' response to questions about experiences of loss through death of significant figures. The scale focuses on indications of mental disorganization and disorientation, which seem to reflect Bowlby's phases of searching and yearning, disorganization and despair. Such indications are, for instance, lapses in the monitoring of reasoning (as is implied in the disbelief that the person is dead, or in the feeling of being causal in the death where no material cause is present), or lapses in the monitoring of discourse (as implied by unusual attention to details surrounding the death, or sudden changes of topic or moves away from the topic). Several studies have reported on the association between parents' unresolved states of mind and their children's disorganized/disoriented behavior in the Strange Situation (Ainsworth \& Eichberg, 1991; Levine, 
Tuber, Slade, \& Ward, 1991; Radojevic, 1994; for a meta-analysis see van IJzendoorn, 1995).

The potential influence of loss of a partner through divorce or through the break-up of a (premarital) romantic relationship has, however, been given less attention by attachment researchers. Hazan and Shaver (1987) conceptualized romantic love as an attachment process, applying Bowlby's and Ainsworth's ideas and findings to the domain of adult love. They translated Ainsworth, Blehar, Waters, and Wall's (1978) descriptions of infant attachment categories into terms appropriate to adult love and asked subjects via a newspaper questionnaire to classify themselves and to answer some questions about their most important love relationship, which could be either a past or a current relationship (see also Feeney, 1994; Feeney \& Noller, 1990; 1991). Hazan and Shaver (1987) found that a smaller percentage of the self-classified secure group had been divorced than of the self-classified insecure groups. It is, however, still unclear how the outcome of their self-report attachment style questionnaire is related to the assessment of subjects' attachment representations by means of the AAI (Crowell et al., 1993; De Haas, Bakermans-Kranenburg, \& van IJzendoorn, 1994).

Researchers studying issues related to separation and divorce align the experiences of separation and divorce with experiences of loss through death more often than attachment researchers seem to do. Weiss (1979a) noted that when marital separation occurred, adults exhibit symptoms of "scparation distress" similar to the symptoms exhibited by young children who have lost an attachment figure. Hansen and Shireman (1986) describe the mourning process after a divorce as "mourning the death of a marriage and the loss of a living partner" (p. 326). Hence, most researchers who study subjects' adjustment processes after divorce or scparation seek alliance with theories about mourning after a loss through death. Wiseman (1975), for instance, paired the five stages of mourning described by Kubler-Ross (denial, anger, bargaining, depression, and acceptance; Kubler-Ross, 1969) with the process of divorce, and Crosby, Gage, and Raymond (1983) empirically found evidence that their subjects, who had experienced separation and divorce, displayed a sequence of feelings and bchavior according to Kubler-Ross' stages. Gray and Shields (1992) used Bowlby's theory of mourning to develop a questionnaire to measure phases of mourning in 123 separated or divorced adults. Nearly all of them could be classified according to Bowlby's phases, and a strong relation was found between length of time of physical separation and phase classification.

A number of researchers report that the bereavement process through 
which divorced and widowed people move has several similar characteristics (e.g., Marris, 1974; Parkes, 1972; Weiss, 1979b), but the two groups differ as well. Crosby et al. (1983) note that the distinguishing characteristic between death and divorce concerns "responsibility." Death bereavement lacks the element of choice which is a sine qua non to divorce. They state that in divorce there is always an element of questioning which is addressed to the central issue, i.e., "Am I doing the right thing?" (p. 16). That may complicate the process of mourning. Petiet (1984) found that separated and divorced women were more depressed than widowed women. Kitston, Lopata, Holmes, and Meyerking (1980) report that both groups felt that they had to make their own lives after the loss, but that the divorced were more likely to be ambivalent toward their ex-spouses than the widowed, and that therefore divorce may actually be the more difficult to adjust to. However, divorcees who report that it was their husbands who most wanted the divorce drew a more positive picture of their spouses than did those women who indicated that they themselves most wanted the divorce. This suggests that adjustment after separation or divorce might be different for those who initiated the break-up of their relationship than for those who were confronted with a partner who did not want to continue the relationship. It may also be the case that certain aspects of personality (e.g., temperament) affect the process of coming to terms with the breakup of a romantic relationship.

The breaking-up before marriage is generally less stressful than the experience of marital disruption. Nevertheless, in essence the same processes of grief and adjustment may occur. Hill, Rubin, and Peplau (1976), who investigated break-ups before marriage among a large sample of college students, report that such a break-up can be a traumatic experience indeed. Unfortunately, they obtained reports of emotional reactions from both partners one year after the break-up of only 15 couples. These data suggest that men were hit harder than women by the break-up, but due to the small number of reports, it remains unclear whether significant differences between the breaker-upper and the broken-up-with existed. Helgeson (1994) followed college students in dating relationships over one semester and found that women adjusted better than men to break-up. Men, but not women, adjusted better to the break-up if they had initiated it. Simpson (1987) found that individuals who were close to their former partner, who had dated the former partner for a long time, and who believed they could not easily acquire an alternative partner tended to experience more pronounced distress following dissolution of the relationship, but this study focuses on the period immediately (i.e., within three months) after the break-up. These studies 
show that young adults may expericnce the break-up of their romantic rclationship as a significant event, which takes placc in an important period of thcir lives.

In our study, we explored the potential influence of loss of a partner through the break-up of a romantic relationship within the framework of adults' attachment representations. First, we examined the relation between AAI classifications and the occurrence of the break-up of romantic relationships. Secondly, we investigated the relation between the subject's AAI classification and whether or not she was the initiator of the break-up. Thirdly, and with a more exploratory aim, we tested whether the AAI's rating scale for unresolved loss through death is suitable as an indicator of an unresolved state of mind in relation to the break-up of romantic relationships as well. We then explored whether resolved and unresolved subjects differed in (1) the number of former relationships, (2) the person who initiated the break-up, and (3) their AAI classification. Lastly, we investigated associations between unresolved state of mind regarding relationships and temperament, and between unresolved states of mind regarding relationships and health.

\section{METHOD}

\section{Subjects}

Eighty-three mothers participated in the study, as part of a larger study of mother-child relationships that required several visits to our laboratory shortly after the first birthday of their child (Bakermans-Kranenburg \& van IJzendoom, 1993). Potential subjects were identified in the city-hall records for a medium-sized city and its neighboring villages in The Netherlands. Criteria for participation were the following: (a) Subjects must bc between 19 and 33 years, (b) they must be living together with a spouse, (c) they must have only one child at the time of their participation, and (d) they must not be working out of the home for more than 24 hours per week. The first criterion has to do with a memory test that will not be reported on here, the second and third criteria reflect our interest in subjects' caregiving characteristics in the larger study. The last critcrion was used to facilitate the mothers' committing to several visits to our lab. The criteria of having a spouse and a child may influence the perception of former romantic relationships. We will pay attention to this issue in the Discussion. Of those women who met our criteria, $53 \%$ did participate. Their mean age was 27.3 years; $55 \%$ of them did not work out of the home 
(a percentage which is quite normal for The Netherlands, sce Clerkx \& van IJzendoorn, 1992); 52\% had a son. The mean educational level was $3.7(S D=0.9)$ on a scale ranging from 1 (less than 6 years of schooling) to 6 (at least 16 years of schooling); all of our subjects had more than 6 years of schooling. During their first visit to our lab, subjects were interviewed with the AAI. Two months later, the subjects performed a nonverbal intelligence test, and they were given a questionnaire on temperament and mental and physical health to be completed at home.

\section{Measures}

Adult Attachment Interview. The AAI is a semistructured interview that probes alternately for descriptions of the past relationship with parents, specific supportive or contradictory memories, and descriptions of current relationships with parents. In addition, questions are asked about subjects' experiences with loss through death of important figures and their feelings about these losses, both as a child and as an adult. We supplemented the AAI with the following questions about the break-up of romantic relationships, after about three-quarters of the questions of the standard AAI. The questions are parallel to the AAI questions concerning the loss of close loved persons through death. (Actually, these are translations of the questions, which were asked in Dutch.)

Have you ever experienced the break-up of a romantic relationship?

If so, How old were you at the time?

Can you recall your feelings at that time?

Have your feelings regarding this brcak-up changed much over timc?

Would you say the break-up of the relationship has had an effect on your adult personality?

Did you experience the break-up of another romantic relationship? (same queries).

Five female interviewers conducted the interviews. The intervicws lasted about an hour and were transcribed verbatim. On the basis of the original AAI questions, scores were assigned for subjects' probable experiences with attachment figures and for their current state of mind with respect to attachment (reflected in, e.g., preoccupied anger, insistence on lack of memory, and coherency of transcript). The interviews were then classified in one of the three adult attachment categories-autonomous, dismissing, and preoccupied. Autonomous adults tend to value attachment 
relationships and to consider them important for their own personality as an adult. They describe attachment-related experiences coherently, whether these experiences were negative or positive. Dismissing adults tend to devalue the importance of attachment relationships for their own lives or to idealize their parents without being able to illustrate positive evaluations of their parents with concrete events demonstrating secure interaction. Preoccupied adults are still very much involved and preoccupied with their past attachment experiences. They may express anger when discussing current relationships with their parents, or may still be attempting to please their parents (Main \& Goldwyn, 1985/1995).

When there was evidence for the continuing presence of unresolved responses to loss through death (through lapses in the monitoring of reasoning and discourse concerning the loss, or through reports of extreme behavioral reactions), a score was assigned for lack of resolution of mourning (LRM, Main et al., 1991). The additional classification unresolved is superimposed on the main classification. A LRM score is also assigned when indices of unresolved responses to abuse by attachment figures are present in a subject's discourse. The two authors, being trained by Main and Hesse and blind to other measures, did the coding. Percentage of agreement between two coders was $81 \%(\kappa=.72)$ when interviews were classified into the three categories-autonomous, dismissing, and preoccupied, and $75 \%(\kappa=.66)$ when the unresolved classification was taken into account $(n=16)$. Several studies demonstrated the AAI's reliability and discriminant validity (Bakermans-Kranenburg \& van IJzendoorn, 1993; Crowell et al., 1993; Sagi et al., 1994).

Answers to the new questions yielded information concerning former romantic relationships. The number of former relationships was determined (intercoder reliability $r=.93, n=15$ ), the person who decided to break up the relationship was identified (intercoder agreement $100 \%, n=$ 10 ), and a score for the resolution of mourning regarding the break-up of romantic relationships was assigned. For this scale, we "translated" the original AAI scale that deals with lack of resolution of mourning due to loss through death into a scale dealing with lack of resolution of mouming due to loss through the break-up of a romantic relationship (the LRM-relationship scale). Thus, we interpreted the following, when occurring in the context of discourse on the specific former relationship, as indicative of an unresolved state of mind due to the break-up of that romantic relationship:

- Indications of disbelief

- Feelings of guilt which are unjustified

- Psychologically confused statements 
- Unusual attention to detail

- Invasion into speech of information regarding the former relationship or break-up

- Poetic phrasing with a memorized quality

- Unfinished sentences

- Sudden changes of topic or moves away from the topic

- Reports of very disorganized or disoriented behavioral responses to the break-up of a relationship

Analogous to the assessment of unresolved state of mind with respect to experiences of loss through death (Main \& Goldwyn, 1985/1995), a rating scale as well as a dichotomy was used. The rating scale ranged from 1 to 9 ; where ratings above a 5 (6-9) were assigned, subjects were classified unresolved $(\mathrm{U})$ regarding former romantic relationships, ratings of 4 and less did not lead to a U classification, and a rating of 5 on the LRM-relationship rating scale left open both possibilities. This is analogous to the LRM scale for unresolved loss (Main et al., 1991). An example is provided in the following. The subject began her answer to our first question about the break-up of her former romantic relationship (at the moment of the interview 14 years ago, when she was 16 years old) with an unfinished sentence ("It was with my best girlfriend that he, eh ..."), then switched to her husband and the town where she lived now, then returned to the girlfriend in question, then recounted what that girlfriend and another friend had told her about her husband, then switched again to the former boyfriend and how she had thought that she had forgiven them, "but that they then again. ..." On the basis of the unfinished sentences and the sudden ungraceful changes of topic this subject was assigned a score of 6 on the LRM-relationship rating scale and was considered Unresolved regarding her former romantic relationship. When subjects had experienced the break-up of romantic relationships more than once, their LRM-relationship score was equal to the highest of the scores that were assigned for the different break-ups. The same procedure is followed when a LRM score is assigned to a subject with more than one loss experience (Main \& Goldwyn, 1994). The intercoder reliability for unresolved state of mind with respect to the break-up of a romantic relationship was satisfactory: On ten cases, percentage of agreement on $U$ versus non- $U$ was $90 \%(\kappa=$ .74 ), and the intercoder agreement for the LRM-relationship rating scale was .76 (Spearman's $r$ ).

Intelligence. We measured subjects' IQ to determine whether differences in discourse concerning break-ups of romantic relationships could be ascribed to differences in subjects' intelligence. IQ was assessed by means of Raven's Standard Progressive Matrices (Raven, 1958). This is a 
nonverbal intelligence test, validated in The Netherlands by Van der Giesen (1957) and Van Weeren (1968). It consists of five series with 12 tasks each, with increasing level of difficulty. Three of those series werc administered.

Temperament. Subjects' temperament was assessed with the EAS questionnaire (Buss \& Plomin, 1984). EAS is the acronym of the dimensions Emotionality, Activity, and Sociability; Emotionality is divided into the subscales Fear, Anger, and Distress. Individual differences on these dimensions are proposed to have genetic roots, to be manifest at a very young age, and to affect subsequent personality development (Buss \& Plomin, 1984). The EAS dimensions appear to be related to the five-factor model of personality (the so-called Big Five), but the structure of this relation is not obvious (John, 1990). In our study, the internal consistency of the five scales (Fear, Anger, Distress, Activity, and Sociability) ranged from alpha $=.57$ to alpha $=.67$. This moderate reliability might be due to the small number of items per scale (the questionnaire consists of 20 five-point items). Buss and Plomin (1984) do not report on alpha values of the scales, but they report test-retest reliabilities between $r=.75$ and $r=$ .85 .

Mental and physical health. We administered the AGV-28 (Ormel \& Giel, 1984) to determine the subjects' mental and physical health. The AGV-28 is a Dutch translation of the General Health Questionnaire (GHQ-28, Goldberg \& Hillier, 1979), and is validated for The Netherlands (Ormel \& Giel, 1984). The 28 four-point Likert-type items concern somatic symptoms, anxiety and insomnia, social dysfunction, and symptoms of depression. The validity of the GHQ as a screen for the presence or absence of functional non-psychotic psychopathology has been firmly established (see Goldberg \& Huxley, 1980; Romans-Clarkson, Walton, Herbison, \& Mullen, 1988). In our sample, the questionnaire showed good internal consistency, Cronbach's alpha $=.87$.

\section{RESULTS}

Number of former relationships. Of the 83 women in our sample, 38 subjects ( $46 \%$ ) had experienced the break-up of a romantic relationship once or more. Thirty of them $(79 \%)$ experienced this only once, seven $(18 \%)$ reported on two former relationships, and one subject $(3 \%)$ went through the break-up of a romantic relationship four times. One subject had been married for some years, three subjects had lived together with their partners (two of them for one ycar, one for three years), and another subject had been pregnant of her former (maltreating) partner and had 
had an abortion. The sample consisted of 20 dismissing, 46 autonomous, and 17 preoccupied subjects. Of those subjects who had experienced break-ups of relationships, eight were classified as dismissing, 24 as autonomous, and six as preoccupied. Autonomous, dismissing, and preoccupied subjects did not differ in the number of former romantic relationships they reported, $F(2,81)=1.76, p=.18$. With the classification as unresolved due to loss taken into account, 15 subjects were classified as dismissing, 41 as autonomous, 13 as preoccupied, and $14^{1}$ as unresolved in the whole sample, and of those subjects who had experienced break-ups of relationships five were classified as dismissing, 20 as autonomous, three as preoccupied, and 10 as unresolved regarding a loss through death. Unresolved subjects tended to report slightly more experiences of former romantic relationships, $F(3,81)=2.34, p=.08$. Contrasting the unresolyed subjects with the others revealed a significant difference, $t(d f=18.0)=-2.25, p=.04$ (separate variance estimate). The number of former relationships was not related to the subjects' mental and physical health, nor to temperamental variables, age, educational level, or intelligence.

Person who initiated the break-up. Half of the subjects $(n=19)$ reported that they themselves decided to break up the relationship. An association between the number of former relationships and the person who initiated the break-up (the subject or her former partner) was not found. Interestingly, there was an association between attachment category and initiative to break up the relationship, $\chi^{2}(n=38, d f=2)=8.2, p=.01^{2}$ (see Table 1). All subjects classified as preoccupied (whether or not they received an additional classification as unresolved with respect to loss through death) reported that they decided to break up the relationship themselves. Subjects who initiated the break-up did not differ from subjects whose former partners decided to break up the relationship on temperament, mental and physical health, age, education, or intelligence.

lOne subject was classified as unresolved regarding abuse by her parents rather than regarding a loss through death. Analyses with and without this subject did not reveal different results, except for the number of former relationships; the contrast between the unresolved subjects without this one subject $(n=13)$ and the other subjects did not reveal a significant difference, $l(d f=15.9)=-2.06, p=$ .06 (separate variance estimate).

${ }^{2}$ In this paper, all cross-tabulations with expected frequencies less than five in more than $20 \%$ of the cells were re-analyzed with the computer program Fisher (Verbeek \& Kroonenberg, 1985, 1990), which computes the exact significance level for the $\chi^{2}$ test and in some cases a Monte Carlo estimation of the significance level. In cases of discrepant results we present exact $p$ values. 
Unresolved state of mind regarding relationships. Subjects who had experienced the break-up of a romantic relationship once or more were assigned a score for unresolved state of mind regarding relationships. As mentioned in the Method section, subjects who had experienced the breakup of romantic relationships more than once received the highest of the scores that were assigned for the different break-ups as score for their lack of resolution of mourning the break-up of romantic relationships (their LRM-relationship score). The mean score of the 38 subjects with experiences of break-ups was $3.43(S D=1.94, \operatorname{Min} 1, \operatorname{Max} 8)$. A larger number of former relationships tended to be related to a higher score on the LRM-relationship scale $(r=.25, p=.08)$. LRM-relationship scores were not influenced by the person who initiated the break-up. No differences in LRM-relationship scores were found among the three AAI categories, $F(2,35)=0.54, p=.59$, nor among the four AAI categories including the Unresolved (regarding a loss through death) classification, $F(3,37)=$ $1.72, p=.18$.

Subjects' mental and physical health and subjects' intelligence and age were not related to their scores on the LRM-relationship scale, either, but higher LRM-relationship scores were related to a higher educational level $(r=.27, p=.05)$. Therc were also significant associations between scores on the LRM-relationship scale on the one hand, and scores on some of the temperament subscales on the other hand: Subjects with higher scores on the LRM-relationship scale scored higher on Sociability $(r=.46, p=$

TABLE 1. Association Between AAl-Classifications and the Person Who Initiated the Break-Up

Adult Attachment Representation

Dismissing Autonomous Preoccupied Total

Person Who Initiated the Break-Up

\begin{tabular}{lrrrr}
\hline Self & 2 & 11 & 6 & 19 \\
& $-1.6^{1}$ & -0.7 & 2.7 & \\
Partner & 6 & 13 & 0 & 19 \\
& 1.6 & 0.7 & -2.7 & \\
\hline Total & 8 & 24 & 6 & 38 \\
\hline
\end{tabular}

$\chi^{2}(n=38, d f=2)=8.2, p=.01$

Haberman's adjusted standard residuals 
$.002)$, and lower on both Fear $(r=-.52, p<.001)$ and Distress $(r=-.27$, $p=.05)$.

On the basis of answers to the question about the break-up of romantic relationships, the subjects could be divided into three subgroups: subjects who were resolved regarding former relationships $(n=28$; these subjects received scores of 1-5 on the LRM-relationship scale), those unresolved regarding former relationships $(n=10$; these subjects received scores of 5-9 on the LRM-relationship scale), and those who had not experienced the break-up of a romantic relationship $(n=45)$. The distribution of the three AAI classifications (dismissing, autonomous, and preoccupied) were about the same in the three subgroups, $\chi^{2}(N=83, d f=4)=3.38, p=.50$, but the distributions of AAI classifications in these three subgroups appeared to be different when the classification as unresolved regarding a loss through death was taken into account as a separate category, $\chi^{2}(N=$ $83, d f=6$ ) $=15.24, p=.02$ (see Table 2). Autonomous subjects were more often unresolved regarding former romantic relationships, and subjects classified as unresolved due to loss through death were more often in the subgroup of subjects who experienced the break-up of former romantic relationships but were not unresolved regarding them. In fact, all subjects with former relationships who were classified as unresolved due to a loss through death, were classified as not unresolved regarding the break-up of

TABLE 2. Association Between AAI-Classifications and the Break-Up of Former Romantic Relationships

Adult Attachment Representation

Former

Dismissing Autonomous Preoccupied Unresolved Total

Relationships

\begin{tabular}{lrrrrr}
\hline No former & 10 & 21 & 10 & 4 & 45 \\
relationships & $1.1^{1}$ & -0.5 & 1.8 & -2.1 & \\
$\begin{array}{l}\text { One or more former } \\
\text { relationships, }\end{array}$ & 4 & 12 & 2 & 10 & 28 \\
not unresolved & -0.6 & -0.9 & -1.5 & 3.3 & \\
$\begin{array}{l}\text { One or more former } \\
\text { relationships, }\end{array}$ & 1 & 8 & 1 & 0 & 10 \\
unresolved & -0.7 & 2.1 & -0.5 & -1.5 & \\
\hline Total & 15 & 41 & 13 & 14 & 83 \\
\hline
\end{tabular}

$x^{2}(n=83, d f=6)=15.24, p=.02$

Haberman's adjusted standard residuals 
their relationships (see Table 2). Subjects' classifications as unresolved regarding former relationships were not influenced by the person who initiated the break-up, $\chi^{2}(n=38, d f=1)=0.54, p=.46$. Interestingly, the four subjects who had been married or lived together were considered unresolved regarding their former relationships, and the same was true of the subject who had been pregnant.

No differences among the three subgroups were found in age, education, or intelligence (see Table 3). Neither did they differ in terms of their mental and physical health, $F(2,80)=1.42, p=.25$ (see Table 3). Significant differences were found on the temperament scales. Although subjects did not differ on Activity, Anger, and Distress, they did differ on Sociability, $F(2,80)=3.42, p=.04$, and on Fear, $F(2,80)=9.13, p<.001$. Subjects who were unresolved regarding the break-up of a relationship were more sociable and less fearful (see Table 3).

\section{DISCUSSION}

This study integrated the experience of the break-up of a romantic relationship into research on adults' attachment representations. The AAI scoring system for unresolved loss could reliably be used for determining whether subjects had come to terms with the break-up of a romantic relationship. Scores on this LRM-relationship scale were not related to subjects' intelligence. Subjects classified as unresolved due to loss through death were more likely to have experienced the break-up of a romantic relationship. At the same time, they were more often classified as not unresolved regarding these break-ups. They might have been so involved in their successful coming to terms with their former relationships, that they therefore remained unresolved regarding their experiences of loss; or they may have been overwhelmed by their lack of resolution of mourning due to loss, and therefore had not yet started to deal with the break-up of their former relationships. This "failed mourning" is not rated with the LRM-relationship scale. The finding that autonomous subjects were more often unresolved regarding former romantic relationships cannot easily be interpreted. It could be the case that autonomous subjects were more willing to reveal the fact that they did not yet complete resolution regarding former relationships as they are considered to communicate more openly about negative emotions than insecure adults. However, in that case we would also expect an elevated score for their lack of resolution of mourning regarding losses through death, and that was not the case: Autonomous subjects had lower scores on unresolved state of mind with respect to experiences of loss through death, $F(2,80)=3.44, p=.04$. 


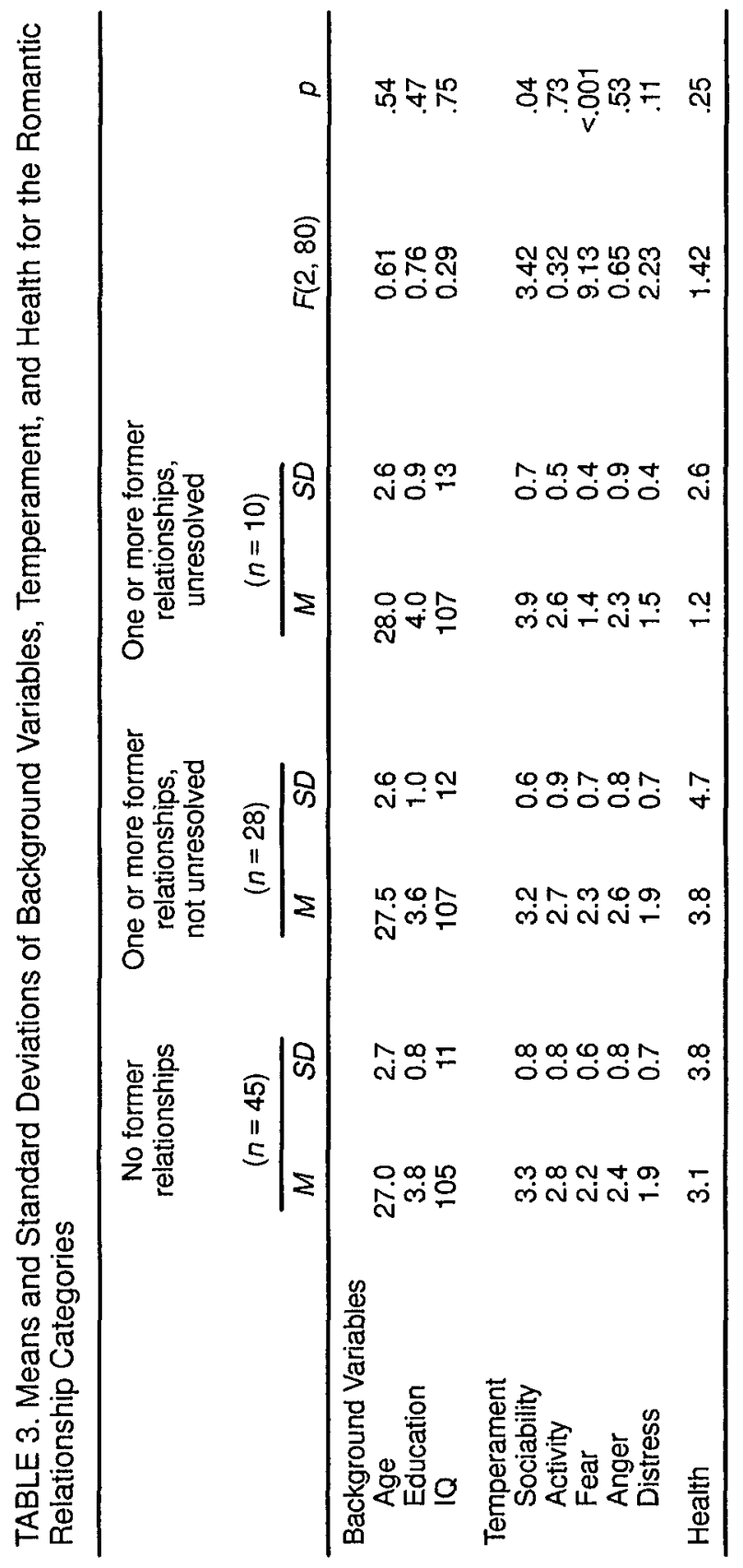


Furthermore, it should be noted that the difference among the AAI categories in lack of resolution of mourning the break-up of former relationships was only found when the dichotomy resolved versus unresolved regarding relationships was used. There were no significant differences in the continuous LRM-relationship scale scores.

The unexpected result that subjects who were classified as unresolved with respect to the break-up of a romantic relationship appeared to be more sociable and less fearful could partly be due to the fact that most of them were classificd as autonomous on the basis of their AAI (see Table 2). Autonomous subjects tended to score higher on Sociability than other subjects (see De Haas et al., 1994).

Half of the subjects who experienced the break-up of a relationship indicated that they had initiated the break-up. Logically, this is exactly what one should expect to find. Hill et al. (1976) found more female-initiated break-ups in their study of premarital relationships. Although they report a tendency for respondents to say that they themselves, rather than their partners, were the ones who wanted the break-up, this seems not the case in our study. Preoccupied subjects appeared to be the persons who never let their partners decide to break up their relationship. This remarkable outcome can be related to Patrick, Hobson, Castle, Howard, and Maugham's (1994) finding that subjects with "borderline" personality disorders, who tend to start and break up intimate relationships abruptly, were most often classified as preoccupied on the basis of their AAIs. Kessler (1975) suggests that the initiator has the advantage of preparing $\mathrm{him} / \mathrm{herself}$ for the separation and single life. In the divorce and separation literature to date, however, research on the effect of initiator status is marked by conflicting results and conclusions (Rossiter, 1991). In our study, subjects' classifications as unresolved regarding former relationships were not influenced by the person who initiated the break-up.

Of course, the breaking up before marriage is generally less stressful than the experience of marital disruption. It could be remarked that all of our subjects were married to new partners at the moment of our study, and might, therefore, not be representative of persons with former relationships. Their current life circumstances of living together with a spouse and having a baby may bias their memories of former romantic relationships. Saul and Sherman (1984), however, found no significant differences on measures of grief and adjustment between those who had remarried and those who remained single.

Many of our subjects (54\%) did not at all experience the break-up of former romantic relationships. The low percentage of subjects who experienced the break-up of former relationships reflects the fact that subjects 
generally reported on rather serious romantic relationships, and not on brief affairs. Nevertheless, there may have been differences in the seriousness of the past relationships reported on by the subjects. The four subjects who had been married or lived together with a partner werc classified as unresolved regarding their former relationships. This implies some external validity for the LRM-relationship scale.

Our study needs to be complemented by investigations of larger and more homogeneous samples of divorced subjects. This seems especially important as failure to come to terms with the end of a relationship has been linked to stresses in parenting (Wallerstein \& Kelly, 1980). We believe to have demonstrated that the research on adults' attachment representations provides a fruitful framework to study this topic.

\section{REFERENCES}

Ainsworth, M.D.S., Blehar, M.C., Waters, E., \& Wall, S. (1978). Patterns of attachment: A psychological study of the Strange Situation. Hillsdale, NJ: Erlbaum.

Ainsworth, M.D.S., \& Eichberg, C. (1991). Effects on infant-mother attachment of mother's unresolved loss of an attachment figure or other traumatic experience. In C.M. Parkes, J. Stevenson-Hinde, \& P. Marris (Eds.), Attachment across the life cycle (pp. 160-183). London: Tavistock.

Bakermans-Kranenburg, M.J., \& van IJzendoorn, M.H. (1993). A psychometric study of the Adult $\Lambda$ ttachment Interview: Reliability and discriminant validity. Developmental Psychology, 29(5), 870-879.

Bowlby, J. (1969/1984). Attachment, Vol. 1 of Attachment and loss (2nd ed.). Harmondsworth: Penguin.

Bowlby, J. (1973/1980). Separation: Anxiety and anger, Vol. 2 of Attachment and loss. Harmondsworth: Penguin.

Bowlby, J. (1977). The making and breaking of affectional bonds-part 1: Aetiology and psychopathology in the light of attachment theory. British Journal of Psychiatry, 130, 201-210.

Bowlby, J. (1980). Loss: Sadness and depression, Vol. 3 of Attachment and loss. Ilarmondsworth: Penguin (1981).

Buss, A.H., \& Plomin, R. (1984). Temperament: Early developing personality traits. IIillsdale, NJ: Erlbaum.

Clerkx, L.E., \& van IJzendoorn, M.H. (1992). Child care in a Dutch context: On the history, current status, and evaluation of nonmaternal child care in The Netherlands. In M.E. Lamb, K.J. Sternberg, C.-P. Hwang, \& A.G. Broberg (Eds.), Child care in context: Crosscultural perspectives (pp. 55-81). Hillsdale, NJ: Erlbaum.

Crosby, J.F., Gage, B.A., \& Raymond, M.C. (1983). The grief resolution process in divorce. Journal of Divorce, 7, 3-18. 
Crowell, J.A., Waters, E., Treboux, D., Posada, G., O'Connor, E., Colon-Downs, C., Feider, O., Fleischman, M., Gao, Y., Golby, B., Lay, K.-L., \& Pan, H. (1993, April). Validity of the Adult Attachment Interview: Does it measure what it should? Poster symposium, presented at the Biennial Meeting of the Society for Research in Child Development, New Orleans, LA.

De Klaas, M.A., Bakermans-Kranenburg, M.J., \& van IJzendoorn, M.H. (1994). The Adult Attachment Interview and questionnaires for attachment style, temperament, and memories of parental behavior. The Journal of Genetic Psychology, 155(4), 471-486.

Doka, K.J. (1986). Loss upon loss: The impact of death after divorce. Death Studies, 10, 441-449.

Feeney, J.A. (1994). Attachment style, communication patterns, and satisfaction across the life cycle of marriage. Personal Relationships, 1, 333-348.

Feeney, J.A., \& Noller, P. (1990). Attachment style as a predictor of adult romantic relationships. Journal of Personality and Social Psychology, 58, 281-291.

Feeney, J.A., \& Noller, P. (1991). Attachment style and verbal descriptions of romantic partners. Journal of Social and Personal Relationships, 8, 187-215.

George, C., Kaplan, N., \& Main, M. (1985). Adult attachment interview. Unpublished manuscript, University of California, Berkeley.

Goldberg, D.P., \& Hillier, V.F. (1979). A scaled version of the GIIQ. Psychological Medicine, 9, 139-145.

Goldberg, D.P., \& IIuxley, O.P. (1980). Mental illness in the community. London: Tavistock.

Gray, C.A., \& Shields, J.J. (1992). The development of an instrument to measure the psychological response to separation and divorce. Journal of Divorce \& Remarriage, 17, 43-56.

Hansen, L.B., \& Shireman, J.F. (1986). The process of emotional divorce: Examination of theory. Social Casework, 67, 323-331.

IIazan, C., \& Shaver, P. (1987). Romantic love conceptualized as an attachment process. Journal of Personality and Social Psychology, 52, 511-524.

Helgeson, V.S. (1994). Long-distance romantic relationships: Sex differences in adjustment and breakup. Personality and Social Psychology Bulletin, 20, 254-265.

IIill, C.T., Rubin, Z., \& Peplau, L.A. (1976). Breakups before marriage: The end of 103 affairs. Journal of Social Issues, 32, 147-168.

John, O.P. (1990). The "Big Five" factors taxonomy: Dimensions of personality in the natural language and in questionnaires. In L.A. Pervin (Ed.), Handbook of personality: Theory and research (pp. 66-100). New York: Guilford Press.

Kessler, S. (1975). The American way of divorce. Chicago: Nelson-Hall.

Kitston, G.C., Lopata, H.Z., Holmes, W.M., \& Meyerking, S.M. (1980). Divorcces and widows: Similarities and differences. American Journal of Orthopsychiatry, 50, 291-301.

Kubler-Ross, E. (1969). On death and dying. New York: W.W. Norton. 
Levine, L.V., Tuber, S.B., Slade, A., \& Ward, M.J. (1991). Mothers' mental representations and their relationship to mother-infant attachment. Bulletin of the Menninger Clinic, 55, 454-469.

Main, M., DeMoss, A., \& Hesse, E. (1991). Unresolved (disorganized/disoriented) states of mind with respect to experiences of loss. In M. Main \& R. Goldwyn, Adult Attachment rating and classification systems. Unpublished manuscript, University of California, Berkeley.

Main, M., \& Goldwyn, R. (1985/1995). Adult Attachment Classification System. Unpublished manuscript, University of California, Berkeley.

Marris, P. (1974). Loss and change. New York: Pantheon Books.

Ormel, J., \& Giel, R. (1984). AGV-28 (vertaalde en bewerkte GHW-28) [AGV-28. Translated and adapted GHQ-28]. Groningen, The Netherlands: University of Groningen.

Parkes, C. (1972). Bereavement: Studies of grief in adult life. New York: International University Press.

Patrick, M., Hobson, R.P., Castle, D., Howard, R., \& Maugham, B. (1994). Personality disorder and the mental representation of early social experience. Development and Psychopathology, 6, 375-388.

Petiet, C.A. (1984, April). Grief in separated, divorced, and widowed women: Similarities and differences. Paper presented at the Annual Meeting of the Western Psychological Association, Los Angeles, CA.

Radojevic, M. (1994). Mental representations of attachment among prospective Australian fathers. Australian and New Zealand Journal of Psychiatry, 28, 505-511.

Raven, J.C. (1958). Standard progressive matrices: Sets $A, B, C, D$, and $E$. London: Lewis.

Romans-Clarkson, S.E., Walton, V.A., Herbison, G.P., \& Mullen, P.E. (1988). Marriagc, motherhood, and psychiatric morbidity in New Zealand. Psychological Medicine, 18, 983-990.

Rossiter, A.B. (1991). Initiator status and separation adjustment. Special issue: Marital instability and divorce outcomes: Issues for therapists and educators. Journal of Divorce \& Remarriage, 15, 141-155.

Sagi, A., van IJzendoorn, M.H., Scharf, M., Koren-Karie, N., Joels, T., \& Mayeseless, O. (1994). Stability and discriminant validity of the Adult Attachment Interview: A psychometric study in young Israeli adults. Developmental Psychology, 30, 988-1000.

Saul, S.C., \& Sherman, A. (1984). Divorce grief and personal adjustment in divorced persons who remarry or remain single. Journal of Divorce, 7, 75-85.

Simpson, J.A. (1987). The dissolution of romantic relationships: Factors involved in relationship stability and emotional distress. Journal of Personality and Social Psychology, 53, 683-692.

Tomko, B. (1983). Mourning the dissolution of the dream. Social Work, 28, 391-392.

Van der Giesen, R.W. (1957). Enkele aspecten van het probleem der predictie in de psychologie, speciaal met het oog op de selectie van militair personeel 
[Some aspects of the problem of prediction in psychology, especially in consideration of selecting military staff]. Lisse, The Netherlands: Swets \& Zeitlinger.

van IJzendoorn, M.H. (1995). Adult attachment representations, parental responsiveness, and infant attachment: A meta-analysis on the predictive validity of the Adult Attachment Interview. Psychological Bulletin, 117, 387-403.

Van Weeren, P. (1968). Uitkomsten van het psychologisch onderzoek omtrent milieu, schoolkeuze en schoolgeschiktheid in Amstcrdam, Twente, Friesland en Noord-Brabant [A study on socio-economic status and scholastic aptitude in some parts of The Netherlands]. In F. van Heek (Ed.), Het verborgen talent [The hidden talent] (pp. 126-151). Meppel, The Netherlands: Boom.

Wallerstein, J.S., \& Kelly, J.B. (1980). Surviving the breakup. New York: Basic Books.

Weiss, R. (1979a). The emotional impact of marital separation. In G. Levinger \& O.C. Moies (Eds.), Divorce and separation (pp. 204-205). New York: Basic Books.

Weiss, R. (1979b). Going it alone: The family life of social situation of single parents. New York: Basic Books.

Wiseman, R.S. (1975). Crisis theory and the process of divorce. Social Casework, $56,205-212$. 